\title{
Correlation of retinal nerve fibre layer and macular thickness with serum uric acid among type 2 diabetes mellitus
}

\author{
Munisamy-Naidu Vinuthinee-Naidu ${ }^{1,2,3}$, Embong Zunaina ${ }^{1,2^{*}}$, Anuar Azreen-Redzal ${ }^{3}$ and Naing Nyi-Nyi ${ }^{2,4}$
}

\begin{abstract}
Background: Uric acid is a final breakdown product of purine catabolism in humans. It's a potent antioxidant and can also act as a pro-oxidant that induces oxidative stress on the vascular endothelial cells, thus mediating progression of diabetic related diseases. Various epidemiological and experimental evidence suggest that uric acid has a role in the etiology of type 2 diabetes mellitus. We conducted a cross-sectional study to evaluate the correlation of retinal nerve fibre layer (RNFL) and macular thickness with serum uric acid in type 2 diabetic patients.

Methods: A cross-sectional study was conducted in the Eye Clinic, Hospital Universiti Sains Malaysia, Kelantan between the period of August 2013 till July 2015 involving type 2 diabetes mellitus patients with no diabetic retinopathy and with non-proliferative diabetic retinopathy (NPDR). An evaluation for RNFL and macular thickness was measured using Spectralis Heidelberg optical coherence tomography. Six $\mathrm{ml}$ of venous blood was taken for the measurement of serum uric acid and glycosylated haemoglobin ( $\left.\mathrm{HbA} 1_{\mathrm{C}}\right)$.

Results: A total of 180 diabetic patients were recruited (90 patients with no diabetic retinopathy and 90 patients with NPDR) into the study. The mean level of serum uric acid for both the groups was within normal range and there was no significance difference between the two groups. Based on gender, both male and female gender showed significantly higher level of mean serum uric acid in no diabetic retinopathy group ( $p=0.004$ respectively). The mean serum uric acid was significantly higher in patient with $\mathrm{HbAl}_{C}<6.5 \%(p<0.031)$. Patients with NPDR have thicker RNFL and macular thickness compared to patients with no diabetic retinopathy. However, only the RNFL thickness of the temporal quadrant and the macular thickness of the superior outer, inferior outer and temporal outer subfields were statistically significant ( $p=0.038, p=0.004,0.033$ and $<0.001$ respectively). There was poor correlation between RNFL and macular thickness with serum uric acid in both the groups.
\end{abstract}

Conclusion: Serum uric acid showed a poor correlation with RNFL and macular thickness among type 2 diabetic patients.

Keywords: Diabetic retinopathy, Retinal nerve fibre layer thickness, Macular thickness, Serum uric acid, Glycosylated haemoglobin

\footnotetext{
* Correspondence: zunaina@usm.my

${ }^{1}$ Department of Ophthalmology, School of Medical Sciences, Universiti Sains

Malaysia, 16150 Kubang Kerian, Kelantan, Malaysia

${ }^{2}$ Hospital Universiti Sains Malaysia, Jalan Raja Perempuan Zainab II, 16150

Kubang Kerian, Kelantan, Malaysia

Full list of author information is available at the end of the article
} 


\section{Background}

Diabetes mellitus is regarded as a pandemic, representing one of the most challenging and major public health problems of the twenty-first century. It has become a global alarming disease not sparing any country thus posing a serious threat to its economy [1]. It has been shown that, prevalence of diabetes is rapidly rising and is a major cause of morbidity and mortality [2].

Diabetic retinopathy is the commonest microvascular complication of diabetes mellitus. It remains the leading cause of preventable blindness across all age-groups and places a significant burden on health services [3]. It's termed as a neurovascular disease which affects both the neuroretinal and microvascular component, and the former is said to be compromised early during diabetic retinopathy followed by microvascular changes [4]. The hallmark of retinal neurodegeneration is neural apoptosis of the retinal ganglion cells which are in the inner retina layer and reactive gliosis involving the astrocytes and Muller cells [5]. It is suggested that the functional changes noticed before the vascular pathology develops are due to direct effect of diabetes on the neural retina instead of breakdown of the blood retinal barrier [4].

Several studies have used electroretinogram (ERG) on the retinal nerve fibre layer (RNFL). An abnormal result suggests early retinal neural dysfunction which in later stages progress to neurodegeneration $[6,7]$. It's also accompanied by deficits in contrast sensitivity, loss of dark adaptation and colour vision disturbances [8]. Risk factors for RNFL degeneration in a diabetic patient are hyperglycemia, oxidative stress and advanced glycation end products [9]. Macular thickness in the presence of diabetic retinopathy has been shown to be thicker compared to normal population. This is also seen in diabetic patient with no demonstrable evidence of retinopathy or macular oedema [10].

Serum uric acid is the product of endogenous and exogenous purine metabolism and its derivatives [11]. In the purine metabolic pathway (Fig. 1), adenosine has vasoactive properties that play a role in retinal blood flow. It generates superoxide nitric oxide which affect the retinal circulation by causing capillary occlusion, apoptosis of pericytes and basement membrane thickening [12]. Xanthine, a substrate of xanthine oxidase, enhances superoxide generation, causing microvascular dysfunction and exert tissue damage resulting in lipid and protein peroxidation [12]. These changes are seen in pathogenesis of diabetic retinopathy. Various epidemiological and experimental evidence suggest that uric acid has a role in the aetiology of type 2 diabetes mellitus [11-13].

From as early as 1950, Griffiths M [14] reported the diabetogenic action of serum uric acid and suggested that it's levels are associated with an increased risk of type 2 diabetic complications. Several other studies have also observed similar findings $[15,16]$. Goldberg $R B$ [17], attributed proatherogenic properties of serum uric acid to be responsible for the pathogenesis of diabetic retinopathy and other diabetic vascular complications. These include activation of endothelial cells \& platelets and increased platelet adhesiveness. Navin S et al. [11] also concluded that poor glycemic control in type 2 diabetes mellitus is associated with an increased serum uric acid level and dyslipidemia, which could be the initial

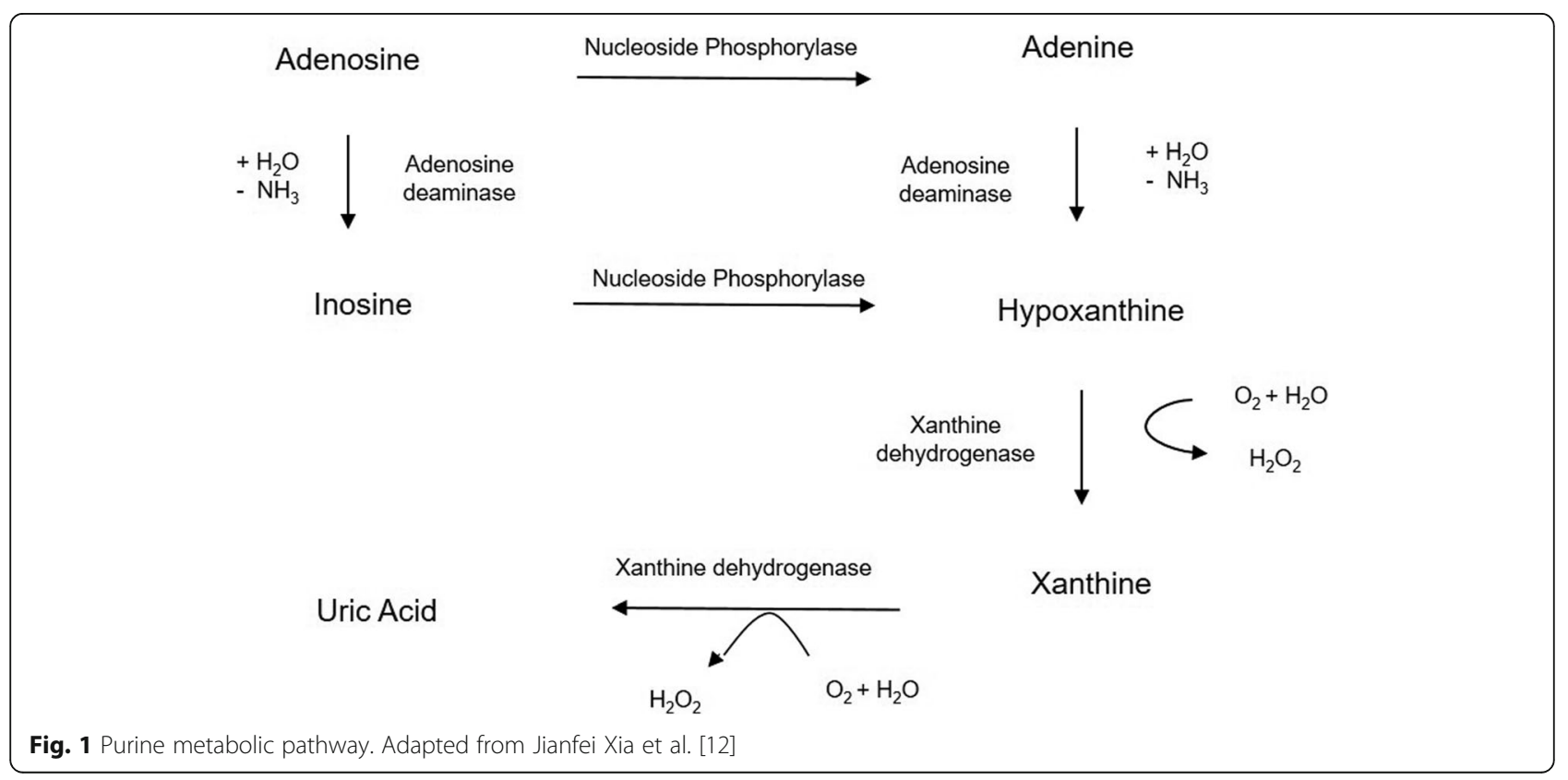


ongoing biochemical change in the complication of diabetes.

In view of numerous evidence suggesting the role of uric acid in diabetic patients, our study was conducted to correlate the RNFL thickness and macular thickness with serum uric acid among type 2 diabetes mellitus patients. To the best of our knowledge, there are no studies done that correlate serum uric acid with RNFL and macular thickness in diabetic patients.

\section{Methods}

A cross-sectional study was carried out on 180 patients with type 2 diabetic mellitus [90 patients with no diabetic retinopathy and 90 patients with non-proliferative diabetic retinopathy (NPDR)] who attended the Eye Clinic, Hospital Universiti Sains Malaysia, Kelantan, Malaysia from August 2013 to July 2015.

Type 2 diabetes mellitus patients aged between 40 and 65 years old with clear media were included. Those patients with optic nerve, retina and macular pathology, NPDR with moderate and severe diabetic macular oedema, previous history of laser, history of intraocular surgery, renal disease and hyperuricemia were excluded from this study.

The demographic data (age, gender and ethnicity) was obtained either from the patient or their medical record. A thorough slit lamp and fundus examination was performed by one identified ophthalmologist to confirm the diagnosis. The classification of diabetic retinopathy was based on the International Diabetic Retinopathy Severity scales [18]. Only one eye of the worst severity was selected.

The RNFL and macular thickness was measured using the Spectralis Spectral-Domain Optical Coherence Tomography (SD-OCT) (Heidelberg Engineering, Heidelberg, Germany). For RNFL thickness analysis, a $3.45 \mathrm{~mm}$ diameter peripapillary ring was measured
(Fig. 2a). All the four quadrants were taken for analysis in this study; superior, inferior, temporal and nasal (Fig. 2b). The macular thickness was determined by using the '6 $\mathrm{mm}$ fast macular mapping' scanning pattern. It consists of a high resolution 19 raster line scan protocol that was applied on an area centered on the fovea with the horizontal lines spaced $240 \mu \mathrm{m}$ apart (Fig. 3a). The Early Treatment Diabetic Retinopathy Study (ETDRS) grid was applied dividing the macula into 9 subfields, encircled by rings of 1, 3 and $6 \mathrm{~mm}$ in diameter. All the subfields were taken for analysis in this study: fovea; superior inner, inferior inner, temporal inner, nasal inner in the second ring; superior outer, inferior outer, temporal outer and nasal outer in the outer ring (Fig. 3b).

Six ml of venous blood was drawn from the median cubital vein for measurement of serum uric acid and glycosylated haemoglobin $\left(\mathrm{HbAl}_{\mathrm{C}}\right)$. The reference normal range for serum uric acid measured in Hospital Universiti Sains Malaysia differs in each gender: Male 180$420 \mu \mathrm{mol} / \mathrm{L} ;$ Female $150-360 \mu \mathrm{mol} / \mathrm{L}$.

\section{Statistical methods}

The statistical analysis was carried out using Statistical Package for Social Sciences (SPSS) Version 22. All values were tested for normal distribution and equal variances. Chi Square test was used for comparison of gender and ethnicity. Independent $\mathrm{t}$-test was used for comparison of age, $\mathrm{HbA} 1_{\mathrm{C}}$, serum uric acid, RNFL thickness and macular thickness. Significance of difference in values was determined by the ' $\mathrm{p}$ ' value $<0.05$. The correlation between RNFL thickness and macular thickness with serum uric acid was tested using Pearson correlation. Significance of correlation was decided based on ' $r$ ' [19] and 'p' values.

\section{Results}

The distribution of demographic data is shown in Table 1 . The male and female gender were not equally distributed

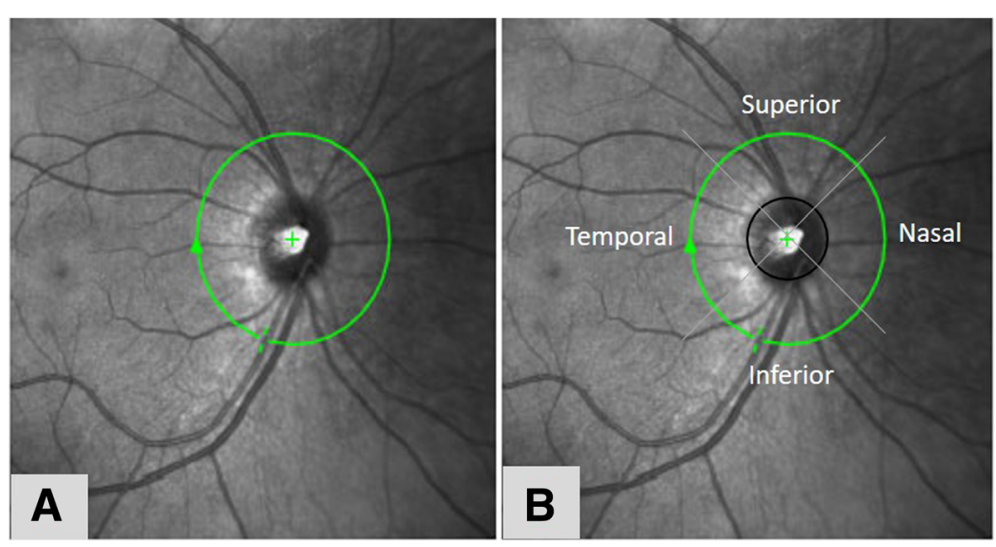

Fig. 2 Centration of peripapillary ring (a) and quadrants (b) for retinal nerve fibre layer measurement 


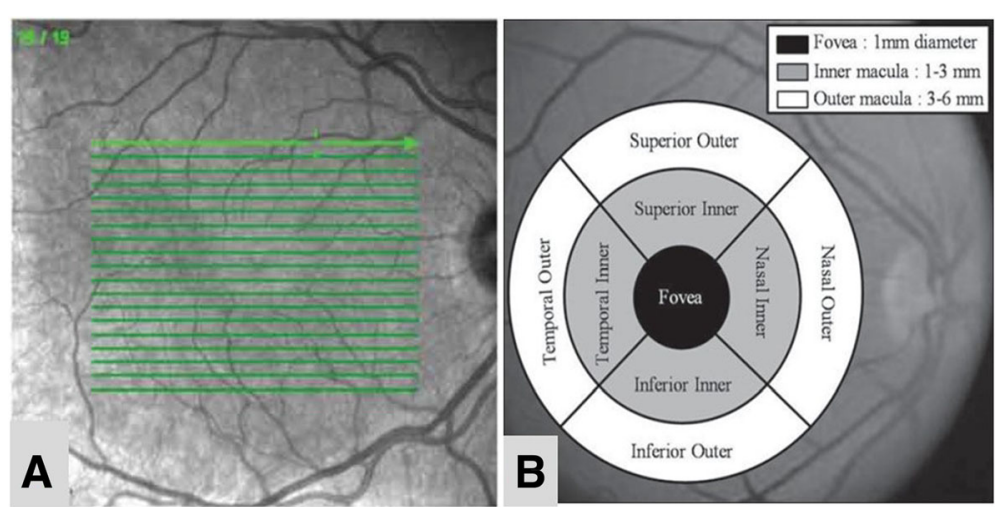

Fig. 3 The ' 6 mm fast macular mapping' with 19 raster line centered at the fovea (a) and the Early Treatment Diabetic Retinopathy Study (ETDRS) grid dividing the macula into 9 subfields (b) for macular thickness measurement

among both groups; however, it was not significant. The majority of the patients were Malay in both the groups. Both the groups showed a poor diabetic control with mean $\mathrm{HbA} 1_{\mathrm{C}}$ more than $6.5 \%$. The $\mathrm{HbA1}_{\mathrm{C}}$ was significantly higher in NPDR (9.59\%, standard deviation (SD) 2.27) compared to no diabetic retinopathy $(7.84 \%$, SD 2.01) $(p<0.001)$.

The mean level of serum uric acid for both the groups was within normal range but at the upper limit. There was no statistically significant difference between the groups $(p=0.220)$ (Table 2). However, based on gender, both male and female patients with no diabetic retinopathy showed a significantly higher level of mean serum uric acid compared to those in NPDR group $(p=0.004$ respectively). The mean level of serum uric acid was significantly higher in those patients with $\mathrm{HbA1c}<6.5 \%$

Table 1 Distribution of age, gender, ethnic group and mean $\mathrm{HbA} 1_{\mathrm{C}}$

\begin{tabular}{lllll}
\hline Characteristics & $\begin{array}{l}\text { No DR } \\
n=90\end{array}$ & $\begin{array}{l}\text { NPDR } \\
n=90\end{array}$ & $\begin{array}{l}\text { t statistic } \\
(\mathrm{df})\end{array}$ & $p$ value \\
\hline $\begin{array}{l}\text { Age (years) } \\
\text { Mean (SD) }\end{array}$ & $52.16(5.87)$ & $51.21(5.20)$ & 1.142 & $0.225^{\mathrm{a}}$ \\
$\begin{array}{c}\text { Gender (n, \%) } \\
\text { Male }\end{array}$ & $51(56.70)$ & $40(44.40)$ & 2.689 & $0.101^{\mathrm{b}}$ \\
$\quad \begin{array}{l}\text { Female } \\
\text { Ethnicity (n, \%) }\end{array}$ & $39(43.30)$ & $50(55.60)$ & & \\
Malay & $73(81.10)$ & $75(83.30)$ & 3.958 & $0.138^{\mathrm{b}}$ \\
Chinese & $11(12.20)$ & $14(15.60)$ & & \\
Indian & $6(6.70)$ & $1(1.10)$ & & \\
HbA1c (\%) & & & & \\
Mean (SD) & $7.84(2.01)$ & $9.59(2.27)$ & 5.467 & $<0.001^{\mathrm{a}}$ \\
\hline
\end{tabular}

DR Diabetic Retinopathy, NPDR Non-Proliferative Diabetic Retinopathy, SD Standard Deviation

${ }^{\mathrm{a}}$ Independent T-test, ${ }^{\mathrm{b}} \mathrm{Chi}$ Square, $p$ value $<0.05$ significant compared to those with HbA1c $\geq 6.5 \%(p=0.031)$ (Table 3).

Patients with NPDR generally have thicker RNFL and macular thickness compared to patients with no diabetic retinopathy. However, only the RNFL thickness of the temporal quadrant and the macular thickness of the superior outer, inferior outer and temporal outer subfields were statistically significant $(p=0.038, p=0.004,0.033$ and $<0.001$ respectively) (Table 4 ).

The RNFL thickness showed a poor negative correlation with serum uric acid in all the quadrants for both the groups except the RNFL thickness of the temporal quadrant of no diabetic retinopathy group showed a poor positive correlation (Table 5). All the macular subfields in the no diabetic retinopathy group showed a poor negative correlation with serum uric acid except the fovea subfield showed poor positive correlation. Whereas, all the macular subfields in the NPDR group showed a poor positive correlation except superior outer subfield showed a poor negative correlation (Table 5).

\section{Discussion}

Uric acid is a final breakdown product of purine catabolism in humans. It's a potent anti-oxidant and can also act as a pro-oxidant that induces oxidative stress on the vascular endothelial cells, thus mediating progression of diabetic related diseases [20]. Various epidemiological and experimental evidence suggest that uric acid has a role in the etiology of type 2 diabetes mellitus [11-13]. We conducted a cross-sectional study to evaluate the correlation of RNFL and macular thickness with serum uric acid in type 2 diabetic patients.

The mean age of our study participants ranged between 51 to 52 years old. This was consistent with several other studies $[21,22]$. In contrast, Eydis Olafsdottir et al. [23] showed the prevalence of no diabetic retinopathy and those with retinopathy in diabetic patients was 
Table 2 Serum uric acid in no diabetic retinopathy and NPDR

\begin{tabular}{|c|c|c|c|c|c|}
\hline \multirow{2}{*}{$\begin{array}{l}\text { Serum uric acid } \\
(\mu \mathrm{mol} / \mathrm{L})\end{array}$} & \multicolumn{2}{|l|}{ Mean (SD) } & \multirow{2}{*}{$\begin{array}{l}\text { Mean difference } \\
(95 \% \mathrm{Cl})\end{array}$} & \multirow{2}{*}{$\begin{array}{l}\text { t statistics } \\
\text { (df) }\end{array}$} & \multirow[t]{2}{*}{$p$ value } \\
\hline & $\overline{N o} D R$ & NPDR & & & \\
\hline Total & $377.53(95.41)$ & 360.09 (94.69) & $(-10.517,45.406)$ & 1.231 & 0.220 \\
\hline Male & 402.55 (102.44) & 391.75 (88.15) & $(-95.068,18.704)$ & -2.958 & 0.004 \\
\hline Female & $344.82(74.63)$ & 334.76 (92.89) & $(-96.402,-19.055)$ & -2.967 & 0.004 \\
\hline
\end{tabular}

Independent t-test, $p$-value $<0.05$ significant

$D R$ Diabetic Retinopathy, NPDR Non-Proliferative Diabetic Retinopathy, SD Standard Deviation, Cl Confidence Interval

slightly in the older age group. However, HanssonLundblad et al. [24], reported there is no association between age and retinopathy. Perhaps, duration of diabetes, is an independent risk factor for occurrence of retinopathy $[21,23]$. Both the gender was not equally distributed in our study. This was like previous studies that reported no significant differences between retinopathy and gender [21, 25].

Most of the participants in our study were Malay. Malaysia has a multiethnic population with three main races; Malay, Chinese and Indian. However, Kelantan is a predominantly Malay village in the north-eastern state of the Peninsular. This perhaps explains the preponderance of Malay participants in our study. From our findings, the NPDR group had poor glycemic control. This was like other studies done at various places [26, 27].

There are several studies that have linked serum uric acid with the pathogenesis and progression of diabetic retinopathy $[13,28]$. In our study, total serum uric acid was higher in no diabetic retinopathy group, but not statistically significant. The serum uric acid was significantly higher in patients with $\mathrm{HbAl}_{\mathrm{C}}<6.5 \%$. This in accordance with previous studies that stated elevated serum uric acid levels during the early stage of impaired glucose metabolism is said to predict the onset of the type 2 diabetes and has been linked to both micro and macrovascular complications $[29,30]$. Bonakdaran S et al. [31], noted a significant correlation between hyperuricemia and $\mathrm{HbA1}_{\mathrm{C}}$. Dehghan A et al. [16] reported high serum uric acid level precedes hyperinsulinemia and diabetes inducing endothelial dysfunction and oxidative stress.

Few studies involving type 2 diabetic patients showed serum uric acid levels correspond to the severity of diabetic retinopathy [32-34]. The serum uric acid level was showed to increase gradually with increase of severity of diabetic retinopathy. Causevic A et al. [35] reported that the serum uric acid level was increased in type 2 diabetes mellitus and associated with insulin resistant syndrome. Moreover, Ashakiran S. et al. [36], noticed that the compensatory hyperinsulinemia [insulin resistant] showed an antiuricosuric effect on the kidneys which lead to increase serum uric acid level.

In contrast, Nan $\mathrm{H}$ et al. [37] mentioned that the serum uric acid and fasting plasma glucose level increases in non-diabetic individuals but showed lower level in diabetic patient. However, Olukoga AO et al. [38] and Segato $\mathrm{T}$ et al. [39], reported no significant association between serum uric acid and diabetic retinopathy. Pfister $\mathrm{R}$ et al. [40], tested eight common genetic variants which were identified as determinant of serum uric acid level on diabetic patients involving a large cohort of European descent. Their results do not support the association of serum uric acid in the development of type 2 diabetes mellitus.

The male gender had higher level of serum uric acid compared to the female gender. We also observed, the mean serum uric acid in both the gender were statistically significant in no diabetic retinopathy than in NPDR. Our findings were in parallel to another study that showed serum uric acid level was much higher in male than female [41]. Evidence regarding estrogen promotes uric acid excretion [42] supports the findings of hyperuricemia among the males. Choi $\mathrm{HK}$ et al. [42], reported that serum uric acid was significantly higher in diabetic male than female. However, this sex predilection it's still controversial. In contrary Causevic A et al. [35], demonstrated there is no effect of gender on serum uric acid levels in diabetic patient.

Table 3 Comparison of mean serum uric acid with $\mathrm{HbA}_{1} \mathrm{C}$

\begin{tabular}{|c|c|c|c|c|c|}
\hline & \multicolumn{2}{|l|}{$\begin{array}{l}\text { Mean (SD) } \\
\mathrm{HbA1}_{\mathrm{C}}\end{array}$} & \multirow[t]{2}{*}{$\begin{array}{l}\text { Mean difference } \\
(95 \% \mathrm{Cl})\end{array}$} & \multirow[t]{2}{*}{$\begin{array}{l}\text { t statistic } \\
\text { (df) }\end{array}$} & \multirow[t]{2}{*}{$p$ value } \\
\hline & $<6.5 \%$ & $\geq 6.5 \%$ & & & \\
\hline Serum uric acid $(\mu \mathrm{mol} / \mathrm{L})$ & $403.70(97.91)$ & $362.11(93.50)$ & $41.577(3.885,79.269)$ & 2.177 & 0.031 \\
\hline
\end{tabular}


Table 4 RNFL and macular thickness in no diabetic retinopathy and NPDR

\begin{tabular}{|c|c|c|c|c|c|}
\hline \multirow[t]{2}{*}{ Quadrants / Subfields } & \multicolumn{2}{|l|}{ Mean (SD) } & \multirow{2}{*}{$\begin{array}{l}\text { Mean difference } \\
(95 \% \mathrm{Cl})\end{array}$} & \multirow{2}{*}{$\begin{array}{l}\text { t statistics } \\
(\mathrm{df})\end{array}$} & \multirow[t]{2}{*}{$p$ valu } \\
\hline & No DR & NPDR & & & \\
\hline \multicolumn{6}{|l|}{ RNFL thickness $(\mu \mathrm{m})$} \\
\hline Superior & $107.76(21.92)$ & $111.52(22.31)$ & $-9.947,3.597$ & -1.126 & 0.262 \\
\hline Inferior & $108.16(22.92)$ & $108.81(25.01)$ & $-7.700,6.968$ & -0.183 & 0.855 \\
\hline Temporal & $71.10(13.71)$ & $75.02(11.33)$ & $-7.621,-0.226$ & -2.092 & 0.038 \\
\hline Nasal & $73.72(15.13)$ & 73.79 (15.19) & $-4.015,5.082$ & 0.231 & 0.817 \\
\hline \multicolumn{6}{|l|}{ Macular thickness $(\mu \mathrm{m})$} \\
\hline Fovea & $262.57(23.44)$ & $262.86(29.34)$ & $-8.110,7.522$ & -0.073 & 0.942 \\
\hline Superior inner & $330.63(17.25)$ & $333.64(28.34)$ & $-9.911,3.889$ & -0.861 & 0.391 \\
\hline Superior outer & $288.37(16.05)$ & $298.07(27.20)$ & $-16.268,-3.313$ & -2.291 & 0.004 \\
\hline Inferior inner & $327.62(19.33)$ & $330.41(28.22)$ & $-9.904,4.326$ & -0.773 & 0.440 \\
\hline Inferior outer & $278.93(22.71)$ & $286.98(27.20)$ & $-15.415,-0.674$ & -2.154 & 0.033 \\
\hline Temporal inner & $320.07(18.20)$ & $323.68(27.93)$ & $-10.547,3.323$ & -1.028 & 0.306 \\
\hline Temporal outer & $274.11(14.05)$ & $284.90(24.38)$ & $-16.641,-4.936$ & -3.638 & $<0.001$ \\
\hline Nasal inner & $334.70(20.00)$ & $366.69(26.62)$ & $-100.056,36.079$ & -0.927 & 0.355 \\
\hline Nasal outer & $306.32(17.90)$ & $311.59(24.49)$ & $-11.576,1.043$ & -0.165 & 0.101 \\
\hline
\end{tabular}

Independent t-test, $p$-value $<0.05$ significant

DR Diabetic Retinopathy, NPDR Non-Proliferative Diabetic Retinopathy, RNFL Retinal Nerve Fibre Layer, SD Standard Deviation, CI Confidence Interval

Table 5 Correlation of RNFL and macular thickness with serum uric acid among type 2 diabetes mellitus patients

\begin{tabular}{|c|c|c|c|c|}
\hline \multirow[t]{3}{*}{ Quadrants / Subfields } & \multicolumn{4}{|c|}{ Serum uric acid $(\mu \mathrm{mol} / \mathrm{L})$} \\
\hline & \multicolumn{2}{|l|}{ No DR } & \multicolumn{2}{|l|}{ NPDR } \\
\hline & $r$ & $p$-value & $r$ & $p$-value \\
\hline \multicolumn{5}{|l|}{ RNFL thickness $(\mu \mathrm{m})$} \\
\hline Superior & -0.078 & 0.467 & -0.113 & 0.288 \\
\hline Inferior & -0.146 & 0.169 & -0.086 & 0.419 \\
\hline Temporal & 0.064 & 0.548 & -0.067 & 0.532 \\
\hline Nasal & -0.034 & 0.751 & -0.069 & 0.519 \\
\hline \multicolumn{5}{|l|}{ Macular thickness ( $\mu \mathrm{m})$} \\
\hline Fovea & 0.012 & 0.912 & 0.219 & 0.038 \\
\hline Superior inner & -0.095 & 0.374 & 0.034 & 0.749 \\
\hline Superior outer & -0.110 & 0.304 & -0.019 & 0.857 \\
\hline Inferior inner & -0.063 & 0.552 & 0.264 & 0.012 \\
\hline Inferior outer & -0.225 & 0.033 & 0.016 & 0.885 \\
\hline Temporal inner & 0.000 & 0.999 & 0.176 & 0.097 \\
\hline Temporal outer & -0.113 & 0.287 & 0.073 & 0.493 \\
\hline Nasal inner & -0.013 & 0.903 & 0.066 & 0.538 \\
\hline Nasal outer & -0.085 & 0.426 & 0.010 & 0.929 \\
\hline
\end{tabular}

Pearson correlation; r: correlation coefficient, $p$-value $<0.05$ significant $D R$ Diabetic Retinopathy, NPDR Non-Proliferative Diabetic Retinopathy, RNFL Retinal Nerve Fibre Layer
As we know, there are various studies that regard diabetic retinopathy as a neurovascular disease whereby the retinal neurodegeneration antedates the microvascular abnormalities $[4,43]$. The retinal nerve fibre loss was contributed by retinal ganglion cell death and axonal degeneration. In our study, the mean RNFL thickness in all the 4 quadrants was thinner in no diabetic retinopathy compared to NPDR. Only the temporal quadrant was statistically significant. Our findings were parallel to some studies $[26,43]$ and in contrast to few other studies [44, 45]. All 9 subfields of the macular region showed similar changes as the RNFL. However, only 3 subfields were statistically significant (superior outer, inferior outer and temporal outer). These results of our studies were consistent with some studies $[13,46]$ and contradictory to few other studies $[47,48]$.

Several studies, including ours, showed presence of neuronal abnormalities at the early stage of diabetes irrespective of the type of optical coherence tomography (OCT) used $[49,50]$. This explains the thinner retina in no diabetic retinopathy and the increase vascular permeability leads to increased retinal thickness. In our study, we have pooled all severity of NPDR grades, gender and age. Like findings found by other studies $[25,50]$, our study assumed that increase in the retinal thickening observed in the NPDR group was due to the insult from hard exudates and retinal hemorrhages leading to accumulation of intra-retinal fluids. This subsequently results in an increased thickness of the RNFL. Although we 
have excluded patients with clinically apparent and extensive retinal oedema, a possible presence of subclinical retinal oedema in our diabetic patients can interfere the OCT measurement. Subclinical macular oedema in which clinically shows absence of macular oedema on slit lamp examination but on OCT shows abnormally increased macular thickness [50].

We found that only the temporal RNFL quadrant showed a mean significant difference. The superior RNFL quadrant also showed a change in the retinal thickness between the no diabetic retinopathy and NPDR groups however it was not significant. The inferior RNFL quadrant showed a minimal change which is almost negligible between the two groups. In the macular thickness, only the outer most ring including the superior, temporal and inferior subfield showed a significant difference. Several studies have observed the RNFL of the superior and temporal quadrants to be thinner than that of the inferior quadrants [51, 52]. These results support the theory that early events of diabetic retinal disease [microaneurysms and acellular capillaries] occur preferentially in the superior temporal quadrant rather than the inferior quadrants. Chung et al. [53] demonstrated hypercapnia resulted in an increase in hemodynamic flow in the superior temporal quadrant. However, the response was not observed in a hyperoxic condition. In contrast, hyperoxia led to a decrease in blood flow to the inferior retina, whereas hypercapnia did not result in an increased flow within this area [53].

The lack of the normal vasoconstrictor response in the superior quadrant could explain; 1) the increased susceptibility of developing micro aneurysms and acellular capillaries in this region and 2) the preferential loss of retinal fibres in this region before diabetic retinopathy becomes clinically detectable [54]. Another study found the superior quadrant to be more predisposed to damage and a higher rate of cellular death, which resulted in RNFL thinning [26]. Our study demonstrated a lack of thinning of the RNFL at the nasal quadrants. This may be due to lack of micro aneurysmal development, hence sparing damage to the RNFL in this region. We assume the differences in the vascular hemodynamics in the macular region might be also the contributing factors to these phenomena of asymmetrical retinal thickness.

Serum uric acid pathogenesis, has been associated with the development and worsening of the diabetic retinopathy [31]. Chien KL et al. [55] and Ishizaka $\mathrm{N}$ et al. [56], suggested that increase level of serum uric acid acts as a predictor for diabetic vascular complications. Oxidative stress is a culprit for the progression of diabetic retinopathy [29]. Serum uric acid conversely can act as an antioxidant [31]. However, Jianfei Xia et al. [57] demonstrated that there was significantly increased concentration of uric acid among diabetic patients and serum uric acid might be a risk factor for diabetic retinopathy. High serum uric acid level was said as a risk factor of type 2 diabetes mellitus. Lowering the serum uric acid with xanthine oxidase inhibitors can reduce the incidence of type 2 diabetes mellitus and its complication but this is still controversial. Anju G et al. [58] in her studies concluded that serum uric acid levels increase in newly diagnosed diabetic patients, thus it can serve as potential biomarker of the glucose metabolism.

We did a correlation between the serum uric acid with RNFL thickness and macular thickness among no diabetic retinopathy and NPDR. Based on our Medline research, our study is the first study to be conducted. Uric acid inspite being an antioxidant in the circulation, it induces oxidative stress in the vascular endothelial cells, thus mediating progression of disease related to diabetic. Oxidative stress is believed to play an important role in the development of vascular complications in type 2 diabetes mellitus [21].

From our study, we did not find any momentous correlation between the RNFL and macular thickness with serum uric acid in both the groups. However, in those patients with no diabetic retinopathy, only the inferior outer macular subfield which had poor negative correlation with serum uric acid showed a statistically significant relationship. This negative relationship indicates that the higher serum uric acid level, the patient is likely to have minimal thinning of the macular region but the relationship is at a lower rate. This must be interpreted cautiously as only one macular subfield showed a significant relationship. From our findings, we postulate that, in no diabetic retinopathy group, the serum uric acid level is higher which is said to precede the type 2 diabetes, and inversely causes thinning of the macular region secondary to retinal neurodegeneration.

In those patients with NPDR, only the central subfield and inferior inner macula showed a fair positive correlation with a significant relationship. This positive significant relationship indicates that the higher serum uric acid level, the patient is likely to have thicker macular but the relationship is at a lower rate. From our findings, we postulate that, in NPDR group, there will be high likely for nephropathy to set in, thus affecting the renal excretion, increases rates of renal reabsorption, increases the excretion of purine metabolism subsequently raises the production of uric acid. The increase in serum uric acid level via the inflammatory process results in progression of diabetic vascular complication, thus causing vascular leakage and indirectly causing an impact to the macular thickness especially in the posterior pole.

There are several limitations found in our studies. The pooling of the severity of NPDR would have led to potential spurious comparisons. Other limitations include not considering the duration of diabetes, no follow up 
given, distribution of race and gender were not equal. We also did not include parameters for kidney dysfunction or diabetic nephropathy that could alter the excretion of uric acid.

\section{Conclusion}

Serum uric acid showed a poor correlation with RNFL and macular thickness among type 2 diabetic patients. A large population cohort study with well distributed ethnicity and gender is needed to observe if there is presence of correlation between serum uric acid with RNFL and macular thickness among type 2 diabetic patients.

\section{Abbreviations \\ Cl: Confidence interval; DR: Diabetic retinopathy; ERG: Electroretinogram; ETDRS: Early Treatment Diabetic Retinopathy Study; HbA1c: Glycosylated haemoglobin; NPDR: Non-proliferative diabetic retinopathy; OCT: Optical coherence tomography; RNFL: Retinal nerve fibre layer; SD: Standard deviation; SD-OCT: Spectral-Domain Optical Coherence Tomography; SPSS: Statistical Package for Social Sciences}

\section{Acknowledgements}

None

\section{Funding}

None

\section{Availability of data and materials}

All data supporting the findings are contained within the manuscript.

\section{Authors' contributions \\ MNVN designed the study protocol, involved in data collection, data analysis and wrote the manuscript. EZ designed the study protocol, involved in data analysis, edited the manuscript, and management of the study. AAR designed the study protocol and involved in data collection. NNN involved in data analysis of the study. All authors read and approved the final manuscript.}

\section{Competing interests}

The authors declare that there is no conflict of interest.

\section{Consent for publication}

Not applicable.

\section{Ethics approval and consent to participate}

The study adheres to the Tenets of the Declaration of Helsinki and the study is approved by the local ethical board the Human Research Ethics Committee Universiti Sains Malaysia [USM/JEPeM/276.2. (4)]. Written informed consent to participate was obtained for each patient prior to the study.

\section{Publisher's Note}

Springer Nature remains neutral with regard to jurisdictional claims in published maps and institutional affiliations.

\footnotetext{
Author details

'Department of Ophthalmology, School of Medical Sciences, Universiti Sains Malaysia, 16150 Kubang Kerian, Kelantan, Malaysia. ${ }^{2}$ Hospital Universiti Sains Malaysia, Jalan Raja Perempuan Zainab II, 16150 Kubang Kerian, Kelantan, Malaysia. ${ }^{3}$ Department of Ophthalmology, Hospital Sultanah Bahiyah, 05460 Alor Setar, Kedah, Malaysia. ${ }^{4}$ Unit of Biostatistics and Research Methodology, School of Medical Sciences, Universiti Sains Malaysia, 16150 Kubang Kerian, Kelantan, Malaysia.
}

Received: 2 October 2016 Accepted: 8 June 2017

Published online: 14 June 2017

\section{References}

1. Hu FB. Globalization of diabetes: the role of diet, lifestyle, and genes. Diabetes Care. 2011;34(6):1249-57.

2. Guariguata L, Whiting D, Weil C, Unwin N. The international diabetes federation diabetes atlas methodology for estimating global and national prevalence of diabetes in adults. Diabetes Res Clin Pract. 2011;94(3):322-32.

3. Tarr JM, Kaul K, Chopra M, Kohner EM, Chibber R. Pathophysiology of diabetic retinopathy. ISRN Ophthalmol. 2013;2013:343560. http://dx.doi.org/ 10.1155/2013/343560

4. Barber AJ, Gardner TW, Abcouwer SF. The significance of vascular and neural apoptosis to the pathology of diabetic retinopathy. Invest Ophthalmol Vis Sci. 2011;52(2):1156-63. doi:10.1167/iovs.10-6293.

5. Kern TS, Barber AJ. Retinal ganglion cells in diabetes. J Physiol. 2008;586(18):4401-8. doi:10.1113/jphysiol.2008.156695.

6. Bronson-Casstain KW, Bearse MA Jr, Neuville J, Jonasdottir S, King-Hooper B, Barez S, et al. Adolescent with type 2 diabetes: early indications for focal retinal neuropathy, retinal thinning, and venular dilation. Retina. 2009;29(5):618-26. doi:10.1097//AE.0b013e31819a988b.

7. Bearse MA Jr, Adams AJ, Han Y, Schneck ME, Ng J, Bronson-Castain K, et al. A multifocal electroretinogram model predicting the development of diabetic retinopathy. Prog Retin Eye Res. 2006;25(5):425-48.

8. Jackson GR, Scott IU, Quillen DA, Walter LE, Gardner TW. Inner retinal visual dysfunction is a sensitive marker of non-proliferative diabetic retinopathy. $\mathrm{Br}$ J Ophthalmol. 2012;96(5):699-703. doi:10.1136/bjophthalmol-2011-300467.

9. Nakamura M, Barber AJ, Antonetti DA, LaNoue KF, Robinson KA, Buse MG, et al. Excessive hexosamines block the neuroprotective effect of insulin and induce apoptosis in retinal neurons. J Biol Chem. 2001;276(47):43748-55.

10. Lattanzio R, Brancato R, Pierro L, Bandello F, laccher B, Fiore T, et al. Macular thickness measured by optical coherence tomography (OCT) in diabetic patients. Eur J Ophthalmol. 2002;12(6):482-7.

11. Navin S, Krishnamurthy N, Ashakiran S, Dayanand CD. The association of hypomagnesia, high normal uricemia and dyslipidemia in the patients with diabetic retinopathy. J Clin Diagn Res. 2013;7(9):1852-4.

12. Xia J, Wang Z, Zhang F. Association between related purine metabolites dan diabetic retinopathy in type 2 diabetic patients. Int J Endocrinol. 2014;2014:651050. doi:10.1155/2014/651050.

13. Kushiyama A, Tanaka K, Hara S, Kawazu S. Linking uric acid metabolism to diabetic complications. World J Diabetes. 2014;5(6):787-95. doi:10.4239/wjd. v5.6.787.

14. Griffiths $\mathrm{M}$. The mechanism of the diabetogenic action of uric acid. J Biol Chem. 1950;184(1):289-98.

15. Niskanen L, Laaksonen DE, Lindstrom J, Eriksson JG, Keinanen-Kiukaanniemi S, Ilanne-Parrika P, et al. Serum uric acid as a harbinger of metabolic outcome in subjects with impaired glucose tolerance: the finish diabetes prevention study. Diabetes Care. 2006;29(3):709-11.

16. Dehghan A, van Hoek M, Sijbrands EJ, Hofman A, Witteman JC. High serum uric acid as a novel risk factor for type 2 diabetes. Diabetes Care. 2008;31(2):361-2.

17. Goldberg RB. Cytokine and cytokine-like inflammation markers, endothelia dysfunction and imbalanced coagulation in development of diabetes and its complications. J Clin Endocrinol Metab. 2009;94(9):3171-82. doi:10.1210/ jc.2008-2534.

18. Wilkinson CP, Ferris FL, Klein RE, Lee PP, Agardh CD, Davis M, et al. Proposed international clinical diabetic retinopathy and diabetic macular edema disease severity scales. Ophthalmology. 2003;110(9):1677-82.

19. Norsa'adah B. Basic statistics: step by step guide using PASW 18. Basic Statistics Kota Bharu. 2011:43-52.

20. Corry DB, Eslami P, Yamamoto K, Nyby MD, Makino H, Tuck ML. Uric acid stimulates vascular smooth muscle cell proliferation and oxidative stress via the vascular renin-angiotensin system. J Hypertens. 2008;26(2):269-75. doi:10.1097/HJH.0b013e3282f240bf.

21. Abougalambou SS, Abougalambou AS. Risk factors associated with diabetic retinopathy among type 2 diabetes patients at teaching hospital in Malaysia. Diabetes Metab Syndr. 2015;9(2):98-103.

22. Tekeli O, Turaçli ME, Atmaca LS, Elhan AH. Evaluation of the optic nerve head with the heidelberg retina tomograph in diabetes mellitus. Ophthalmologica. 2008;222(3):168-72. doi:10.1159/000126079. 
23. Olafsdottir E, Andersson DK, Dedorsson I, Stefansson E. The prevalence of retinopathy in subjects with and without type 2 diabetes mellitus. Acta Ophthalmol. 2014;92(2):133-7. doi:10.1111/aos.12095.

24. Hansson-Lundblad C, Holm K, Agardh E. A small number of older type 2 diabetic patients end up visually impaired despite regular photographic screening and laser treatment for diabetic retinopathy. Acta Ophthalmo Scand. 2002;80(3):310-5.

25. Pradeepa R, Amitha B, Mohan V, Gunesan A, Rema M. Risk factors for diabetic retinopathy in a south Indian type 2 diabetic population - the Chennai urban rural epidemiology study (CURES) eye study 4. Diabet Med. 2008;25(5):536-42. doi:10.1111/j.1464-5491.2008.02423.x.

26. Sugimoto $M$, Sasoh $M$, Ido $M$, Narushima C, Uji $Y$. Retinal nerve fibre layer decrease during glycemic control in type 2 diabetes. J Ophthalmol. 2010;2010:569215. doi:10.1155/2010/569215

27. Cho NH, Kim TH, Woo SJ, Park KH, Lim S, Cho YM, et al. Optimal HbA1c cut off for detecting diabetic retinopathy. Acta Diabetol. 2013;50(6):837-42. doi:10.1007/s00592-013-0452-3.

28. Krizova L, Kalousova M, Kubena A, Benakova H, Zina T, Kovarik Z, et al. Increased uric acid and glucose concentrations in vitreous and serum of patients with diabetic macula odema. Ophthalmic Res. 2011;46(2):73-9. doi:10.1159/000322994

29. Katsiki N, Papanas N, Fonseca VA, Maltezos E, Mikhailidis DP. Uric acid and diabetes: is there a link? Curr Pharm Des. 2013;19(27):4930-7.

30. Chuengsamarn S, Rattanamongkolgul S, Jirawatnotai S. Association between serum uric acid level and microalbuminuria to chronic vascular complications in Thai patients with type 2 diabetes. J Diabetes Complicat. 2014;28(2):124-9. doi:10.1016/j.jdiacomp.2013.12.002.

31. Bonakdaran S, Hami M, Shakeri MT. Hyperuricemia and albuminuria in patients with type 2 diabetes mellitus. Iran J Kidney Dis. 2011;5(1):21-4.

32. Cai $X L$, Wang F, Ji LN. Risk factors of diabetic retinopathy in type 2 diabetic patients. Chin Med J. 2006;119(10):822-6.

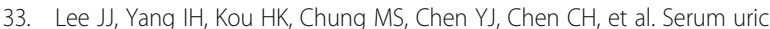
acid concentration in associated with worsening in severity of diabetic retinopathy among type 2 diabetic patients in Taiwan - a 3-year prospective study. Diabetes Res Clin Pract. 2014;106(2):366-72.

34. Liang CC, Lin PC, Lee MY, Chen SC, Shin SJ, Hsiao PJ, et al: Association of serum uric acid concentration with diabetic retinopathy and albuminuria in Taiwanese patients with type 2 diabetes mellitus. Int J Mol Sci. 2016, 17(8). doi:10.3390/ijms17081248.

35. Causevic A, Semiz S, Macic Dzankovic A, Cico B, Duiic T, Malenica M, et al, Relevance of uric acid in progression of type 2 diabetes mellitus. Bosn J Basic Med Sci. 2010;10(1):54-9.

36. Ashakiran S, Krishnamurthy N, Navin S, Patil S. Behaviour of serum uric acid \& lipid profile in relation to glycemic status in proliferative \& non-proliferative diabetic retinopathy. Current Neurobiology. 2010;2(1):57-61.

37. Nan H, Dong Y, Gao W, Tuomilehto J, Qiao Q. Diabetes associated with a low serum uric acid level in a general Chinese population. Diabetes Res Clin Pract. 2007;76(1):68-74

38. Olukoga AO, Eramus RT, Akinlade KS, Okesina AB, Alanamu AA, Abu EA. Plasma urate in diabetes: relationship to glycaemia, glucose disposal, microvascular complications and the variations following oral glucose. Diabetes Res Clin Pract. 1991;14(2):99-105.

39. Segato T, Midena E, Grigoletto F, Zucchetto M, Fedele D, Piermarocchi S, et al. The epidemiology and prevalence of diabetic retinopathy in the Veneto region of north east Italy. Veneto Group for Diabetic Retinopathy. Diabet Med. 1991;8:11-6.

40. Pfister R, Barnes D, Luben R, Forouhi NG, Bochud M, Khaw KT, et al. No evidence for a causal link between uric acid and type 2 diabetes: a Mendelian randomization approach. Diabetologia. 2011;54(10):2561-9. doi:10.1007/s00125-011-2235-0.

41. Rosolowsky ET, Ficociello LH, Maselli NJ, Niewczas MA, Binns AL, Roshan B, et al. High-normal serum uric acid is associated with impaired glomerular filtration rate in non-proteinuria patients with type 2 diabetes. Clin J Am Soc Nephrol. 2008:3(3):706-13. doi:10.2215/CJN.04271007.

42. Choi HK, Ford ES. Haemoglobin A1C, fasting glucose, serum C-peptide and insulin resistance in relation to serum uric acid levels-the third National Health and nutrition examination survey. Rheumatology (Oxford). 2008;47(5):713-7. doi:10.1093/rheumatology/ken066.

43. Chen X, Nie C, Gong Y, Zhang Y, Jin X, Wei S, et al. Peripapillary retinal nerve fibre layer changes in preclinical diabetic retinopathy: a meta-analysis. PLoS One. 2015;10(5):0125919. doi:10.1371/journal.pone.0125919. eCollection 2015
44. Pires I, Bernardes RC, Lobo CL, Soares MA, Cunha-Vaz JG. Retinal thickness in eyes with mild non-proliferative retinopathy in patients with type 2 diabetes mellitus: comparison of measurements obtained by retinal thickness analysis and optical coherence tomography. Arch Ophthalmol. 2002;120(10):1301-6.

45. Massin P, Erginav A, Haouchine B, Mehidi AB, Pagues M, Gaudric A. Retinal thickness in healthy and diabetic subjects measured using optical coherence tomography mapping software. Eur J Ophthalmol. 2002;12(2):102-8

46. Sánchez-Tocino H, Alvarez-Vidal A, Maldonado MJ, Moreno-Montañés J, García-Layana A. Retinal thickness study with optical coherence tomography in patients with diabetes. Invest Ophthalmol Vis Sci. 2002;43(5):1588-94.

47. Bressler NM, Edwards AR, Antoszyk AN, Beck RW, Browning DJ, Ciardella AP, et al. Retinal thickness on stratus optical coherence tomography in people with diabetes and minimal or no diabetic retinopathy. Am J Ophthalmol. 2008;145(5):894-901. doi:10.1016/j.ajo.2007.12.025.

48. Kashani AH, Zimmer-Galler IE, Shah SM, Dustin L, Do DV, Eliott D, et al: Retinal thickness analysis by race, gender and age using Stratus OCT. Am J Ophthalmol. 2010, 149(3):496-502.e1. doi:10.1016/j.ajo.2009.09.025.

49. Barber AJ. A new view of diabetic retinopathy: a neurodegenerative disease of the eye. Prog Neuro-Psychopharmacol Biol Psychiatry. 2003;27(2):283-90.

50. Browning DJ, Fraser CM, Clark S. The relationship of macular thickness to clinically graded retinopatahy severity in eyes without clinically detected diabetic macular odema. Ophthalmology. 2008;115(3):533-9.

51. Lopes de Faria JM, Russ H, Costa VP. Retinal nerve fibre layer loss in patients with type 1 diabetes mellitus without retinopathy. $\mathrm{Br} J$ Ophthalmol. 2002;86(7):725-8.

52. Takahashi H, Goto T, Shoji T, Tanito M, Park M, Chihara E. Diabetes associated retinal nerve fibre damage evaluated with scanning laser polarimetry. Am J Ophthalmol. 2006;142(1):88-94.

53. Chung HS, Harris A, Halter PJ, Kagemann L, Roff EJ, Garzozi HJ, et al. Regional differences in retinal vascular reactivity. Invest Ophthalmol Vis Sci. 1999:40(10):2448-53.

54. Kern TS, Engerman RL. Vascular lesions in diabetes are distributed nonuniformly within the retina. Exp Eye Res. 1995;60(5):545-9.

55. Chien KL, Chen MF, Hsu HC, Chang WT, Su TC, Lee YT, et al. Plasma uric acid and the risk of type 2 diabetes in a Chinese community. Clin Chem. 2008;54(2):310-6.

56. Ishizaka N, Ishizaka Y, Toda E, Nagai R, Yamakado M. Association between serum uric acid, metabolic syndrome, and carotid atherosclerosis in Japanese individuals. Arterioscler Thromb Vasc Biol. 2005;25(5):1038-44.

57. Xia J, Wang Z, Zhang F. Association between related purine metabolites and diabetic retinopathy in type 2 diabetic patients. Int J Endocrinol. 2014:2014:651050. doi:10.1155/2014/651050.

58. Gill A, Kukreja S, Malhotra N, Chhabra N. Correlation of the serum insulin and the serum uric acid levels with the glycated haemoglobin levels in the patients of type 2 diabetes mellitus. J Clin Diagn Res. 2013;7(7):1295-7. doi:10.7860/JCDR/2013/6017.3121.

\section{Submit your next manuscript to BioMed Central and we will help you at every step:}

- We accept pre-submission inquiries

- Our selector tool helps you to find the most relevant journal

- We provide round the clock customer support

- Convenient online submission

- Thorough peer review

- Inclusion in PubMed and all major indexing services

- Maximum visibility for your research

Submit your manuscript at www.biomedcentral.com/submit
) Biomed Central 